\title{
Death Anxiety, Loss, and Grief in the Time of COVID-19
}

\author{
Rachel E. Menzies ${ }^{1 \star}$, Robert A. Neimeyer ${ }^{2}$ and Ross G. Menzies ${ }^{3}$ \\ ${ }^{1}$ School of Psychology, The University of Sydney, Sydney, NSW, Australia, ${ }^{2}$ Portland Institute for Loss and Transition, \\ Portland, OR, USA and ${ }^{3}$ Graduate School of Health, University of Technology Sydney, Sydney, NSW, Australia \\ ${ }^{\star}$ Corresponding author: Rachel E. Menzies, School of Psychology, The University of Sydney, Sydney, NSW, Australia. \\ Email: rmen9223@uni.sydney.edu.au
}

\section{Death and Being Human}

Fear of death has been proposed to be an underlying, central component of the experience of being human (Becker, 1973). Archaeological findings suggest that humans have been gripped by death anxiety for as long as the species has been recording its history (see Menzies (2018) for a review). We have the cognitive capacity to contemplate and anticipate our own death, and so we live our lives 'forever shadowed by the knowledge that we will grow, blossom, and inevitably, diminish and die' (Yalom, 2008, p. 1). Terror Management Theory (TMT) and its extensions propose that we use at least two types of defence mechanisms in the face of death (Burke, Martens, \& Faucher, 2010; Pyszczynski, Greenberg, \& Solomon, 1999). According to TMT, when thoughts of death are conscious we engage in 'proximal defences', which include suppressing these thoughts (e.g. turning off a news report about COVID-19 death tolls), denying one's vulnerability (e.g. thinking "I'm not in a high risk group, so I'll probably be fine"), or trying to prevent death (e.g. cleaning down all home surfaces with antibacterial wipes). On the other hand, research suggests that when thoughts of death leave conscious awareness, we engage in 'distal defences', which involve bolstering three central buffers against the dread of death. First, we increase our adherence to our own cultural worldview (e.g. increased identification with our religion, nation, sporting teams and other 'in-groups', and potentially aggress against those that with different worldviews). Second, we seek to increase our self-esteem (e.g. through goal-directed behaviours consistent with our worldviews). Third, we seek attachment security (e.g. by seeking proximity to loved ones). Hundreds of studies using a 'mortality salience' design, in which participants are primed with death under experimental conditions, support the theoretical claims of TMT and attachment-related theories (see Burke et al. (2010) for a review).

\section{Death Anxiety During COVID-19}

Newton-John, Chambers, Menzies, and Menzies (2020) have argued that COVID-19 presents unique challenges to our species because of the constant reminders of death. They suggest that the everpresent images of death, daily updates of COVID-19 transmissions, and other cues to death (e.g. face masks) mean that we are essentially living in an ongoing, global mortality salience study. Prior to governments closing down cities and borders, reports emerged of individuals choosing to selfisolate with loved ones (Newton-John et al., 2020). As individuals scrambled to prevent the threat of COVID-19 in any way they could, online sales of 'immune boosters', untrialled medicines and similar tonics increased. Anecdotal reports of verbal and physical aggression in grocery stores and racist abuse of individuals with Asian appearance increased as fear swept across the planet (Devakumar, Shannon, Bhopal, \& Abubakar, 2020; Garfin, Silver, \& Holman, 2020). These reports are consistent with laboratory studies showing that reminders of death increase stereotypic thinking about people of other races (Schimel et al., 1999), increase aggression against those who criticise one's nation (McGregor et al., 1998), and lead White participants to hold more favourable reactions to White pride advocates (Greenberg, Schimel, Martens, Solomon, \& Pyszczynski, 2001). Moreover, as fear of (C) The Author(s) 2020. Published by Cambridge University Press 
the virus increased, mental health declined. Findings from several large studies suggest that greater perceived severity of the virus is associated with poorer mental health outcomes ( $\mathrm{Li}$, Yang, Dou, \& Cheung, 2020; Newton-John et al., 2020).

\section{Death, Loss, and Mental Health During COVID-19}

Of course, COVID-19 has not just occasioned potential increases in death anxiety - it also has led to actual increases in sudden death across the globe, as well as the accumulation of numerous secondary losses of financial, social, and personal security. We believe that there are several factors that intensify anxiety associated with the pandemic and make death and grief in the time of COVID-19 particularly challenging. First, as described above, our near-universal immersion in mortality salience heightens anxiety about death for all. This may complicate grief, as increased death anxiety has been associated with poor mental health in several reports (Menzies \& Dar-Nimrod, 2017; Menzies, Sharpe, \& Dar-Nimrod, 2019), and the wordless malaise and physiological perturbation that defines the core of coronavirus anxiety (Lee, 2020) challenge commonplace practices of verbal psychotherapy. Second, death-related losses arising from COVID-19 are compounded by non-death losses, such as global financial strain, massive unemployment, and financial hardship, all of which are also associated with impoverished mental health (Paul \& Moser, 2006). Third, deaths are occurring without normal attachment buffers. Social distancing and lockdowns of communities have limited access to siblings, parents, and close friends. These relationships are critical in moderating our reactions to death (Mikulincer, 2018). Fourth, death from COVID-19 may violate one's core beliefs about the nature of the self, the world, and the future. Specifically, recent research has demonstrated that the profound challenges that the pandemic poses to our assumptive world - such as our beliefs that we possess self-efficacy, that life is in some measure controllable and just, and that the is future is predictable - are strongly associated with our level of coronavirus anxiety or CA (Milman, Lee, \& Neimeyer, 2020a). In contrast, adaptive behaviours such as adhering to social distancing guidelines, sheltering at home and avoiding unnecessary travel have been found to mitigate not only disease transmission but also CA, an effect that appears to be mediated by the way in which such behaviours conserve the intactness of people's core beliefs and their capacity to 'make sense' of a seemingly senseless pandemic (Milman, Lee, \& Neimeyer, 2020b). Indeed, viewed in cognitive behavioural terms, it is striking that behavioural adaptations to the pandemic (such as following widely disseminated social distancing protocols) predict cognitive adaptation (preserving core beliefs and a capacity to make meaning of the crisis), which in turn predicts the physiological symptomatology that defines coronavirus anxiety. This coherent formulation carries helpful implications for psychological assessment and intervention for both CA and associated grief, as we will consider below.

\section{Grief in the Context of COVID-19}

Of the numerous social, economic, and medical impacts of the Coronavirus pandemic, the fatalities resulting from its global spread are the starkest. As this article was posted, the world was approaching 23 million documented infections, and nearly 800,000 deaths from COVID-19 (World Health Organization, 2020). Precisely as predicted by demographic microsimulation forecasts in the earliest weeks of the pandemic in the west, this tsunami of loss raises the spectre of 'the collateral damage that this level of mortality would exact', making it 'important that the burden of bereavement, and its potential mental and physical health consequences, is factored into discussion of the public health challenge facing all nations' (Verdery \& Smith-Greenway, 2020, p. 2). For psychologists, awareness of the distinctive risks for complicated grief associated with such losses is a compelling necessity.

Although grief following the death of a significant attachment figure is a normal human response that should not be considered a psychiatric disorder, an enormous body of research in many countries has led the World Health Organization (2019) to recognize Prolonged Grief Disorder in its most recent edition of the International Classification of Disease (the ICD-11) as a stress-related condition 
- Death of a close person

- Persistent and pervasive grief response accompanied by longing for or preoccupation with deceased

- Intense emotional pain (sadness, guilt, anger, denial, blame, lost sense of self, absence of positive mood, numbness, avoidance of social and other activities)

- Minimum of 6 months after death, exceeding social, cultural, and religious norms

- Significant impairment in personal, family, social, occupational, or other functioning

distinguishable not only from adaptive grieving but also from depression, anxiety, and posttraumatic stress disorders (see Table 1). In this form of life-vitiating, protracted, and anguishing response to loss, mourners struggle with turbulent emotions of longing, guilt, loneliness, and desolation which tangibly impair their ability to function in the contexts of family, work, and the social world for many months beyond the death, and not uncommonly, years. Moreover, ongoing ruminative preoccupation with the lost relationship or the circumstances of the death carries real health risks for a variety of stress-related disorders, cardiac problems, addictions, immune system dysfunction, impaired quality of life, and even suicide (Maercker, Neimeyer, \& Simiola, 2016). And worrisomely, the COVID context of dying presents a perfect storm of converging forces that greatly exacerbate the likelihood of prolonged and complicating grief in its aftermath.

In the past 20 years, a great deal has been learned about risk factors for bereavement complications, which include social isolation, unexpectedness of the death, lower education, or socioeconomic disadvantage in the mourner, insecure and anxious attachment, spiritual struggle in bereavement, inability to make sense of the loss, and lack of institutional and informational support in the care facility in which the death takes place (Neimeyer \& Burke, 2017). Significantly, every one of these factors characterises deaths that occur in the context of the current pandemic - whether or not they result from COVID-19 or other causes. Thus, family and close friends of patients are characteristically isolated from their loved ones at the end of life in an effort to mitigate contagion, reversing decades of progressive policies that as recently as last year generously supported family caregiving. Social distancing and shelter at home protocols combined with travel bans further isolate mourners from one another, even during funerals and memorial services, which commonly are either minimally performed online, postponed indefinitely, or foregone altogether. Especially for the vulnerable elderly or those with compromised health conditions, COVID deaths commonly come suddenly, within mere days or weeks of diagnosis, even with respiratory support. In many nations, coronavirus fatalities disproportionately are concentrated among the urban poor, whose living conditions and more limited access to health care place them at far greater risk of contagion and death. Inability to perform traditional caregiving and offer creaturely comfort and touch at the bedside of the dying challenges attachment imperatives to draw close to loved ones at points of need, leaving in their wake a heavy burden of helplessness, shame, and guilt. Religiously oriented mourners may question the beneficence, power, or intentions of a God they once trusted to care for them and their loved ones, while struggling with estrangement from spiritual communities shuttered during the pandemic. Core elements of people's assumptive worlds and the sense that life is predictable, controllable, just and meaningful are commonly undermined by the pandemic in general, and the context of dying in particular. And overwhelmed and hermetically sealed medical facilities and elder care homes rarely have the luxury to attend compassionately to family needs, as they guard their perimeters and bend all efforts toward urgent care of severely ill patients while attempting to protect the health of their staff. The consequences are entirely predictable: as the present health crisis recedes and the months roll forward, the incidence of prolonged and debilitating grief among those bereaved by any cause in the context of the corona crisis can be expected to skyrocket well above the incidence rate of $10 \%$ documented in pre-pandemic times (Lundorff, Holmgren, Zachariae, Farver-Vestergaard, \& O’Connor, 2017). 


\section{Unfinished Business in Bereavement}

Psychologically speaking, the common denominator of all of the above risk factors is their contribution to unfinished business in bereavement, those unresolved relational issues between the living and the dead that defy simple suasion, reassurance, or well-meaning advice from friends, family, and sometimes therapists to 'move on' (Klingspon, Holland, Neimeyer, \& Lichtenthal, 2015). Programmatic research on these sources of complication have identified two thematic clusters of concern yielding psychometrically clear subscales on a carefully validated measure of the construct, the Unfinished Business in Bereavement Scale (UBBS; Holland, Klingspon, Lichetnthal, \& Neimeyer, 2018), entitled Unfulfilled Wishes (e.g. I wish I could have attended to __'s needs more closely in his/her final days; I wish I had told __ how much s/he meant to me) and Unresolved Conflict (e.g. I never got a chance to resolve a breach in our relationship; I wish I had had the chance to tell __ that I forgive him/her). Taken together with the meaning made of the loss, UB accounts for $50-60 \%$ of the variance in complicated grief symptomatology (Holland et al., 2018) and is especially likely to arise in immediate family relationships (Klingspon et al., 2015).

One obvious injunction for practicing therapists would be to assess such potent predictors of prolonged grief as challenges to meaning or unresolved relational issues by using validated clinical scales (Holland, Currier, \& Neimeyer, 2014; Holland et al., 2018) to assess the character and severity of such issues for the client and to introduce these themes into the work of therapy. Alternatively, open probes in the therapeutic session (e.g. What did you once believe about life that you no longer are so sure of? Are there things that you would want to express or work out with your loved one if you had the chance?) can bring to light issues deserving attention, and open the door to the appropriate selection of any of a plenitude of therapeutic procedures (e.g. directed journaling; imaginal dialogues) for helping clients review and revise their assumptive worlds and address unfinished business with the deceased (Neimeyer, 2012, 2016). Unfortunately, however, developing competence in this existential work of rebuilding worlds of meaning shattered by loss and restoring a sense of attachment security with the dead are rarely given space in graduate curricula, and hence call for further professional development through ongoing professional continuing education. ${ }^{1}$ Given the predictably high demand for professional-level grief therapy arising from the current and future pandemics, we hope that our cognitive behavioural colleagues will join us in embracing this challenge.

Further Reading. Menzies RE, Menzies RG and Iverach L (Eds.) (2018). Curing the Dread of Death: Theory, Research and Practice. Brisbane: Australian Academic Press.

Neimeyer RA (2016). Complicated grief: Assessment and intervention. In J Cook, S Gold and C Dalenberg (Eds.), APA handbook of trauma psychology. Washington, DC: American Psychological Association.

\section{References}

Becker E (1973). The denial of death. New York: Free Press.

Burke BL, Martens A and Faucher EH (2010). Two decades of terror management research: A meta-analysis of mortality salience research. Personality and Social Psychology Review, 14, 155-195.

Devakumar D, Shannon G, Bhopal SS and Abubakar I (2020). Racism and discrimination in COVID-19 responses. The Lancet, 395, 1194. doi:10.1016/S0140-6736(20)30792-3.

Garfin DR, Silver RC and Holman AE (2020). The novel Coronavirus (COVID-2019) outbreak: Amplification of public health consequences by media exposure. Health Psychology, 39, 355-357. doi:10.1037/hea0000875.

Greenberg J, Schimel J, Martens A, Solomon S and Pyszczynski T (2001). Sympathy for the devil: Evidence that reminding Whites of their mortality promotes more favorable reactions to White racists. Motivation and Emotion, 25, $113-133$.

Holland JM, Currier J and Neimeyer RA (2014) Validation of the Integration of Stressful Life Experiences Scale-Short Form in a Bereaved Sample. Death Studies 38, 234-238.

\footnotetext{
${ }^{1}$ Readers interested in pursuing such training might consider annual pre-conference workshops offered by the Association for Death Education and Counseling (www.adec.org), or the American Association for Suicidology (www.suicidology.org), as well as the extensive online and onsite training modules offered by the Portland Institute for Loss and Transition (www.portlandinstitute.org).
} 
Holland JM, Klingspon KL, Lichetnthal WG and Neimeyer RA (2018). The Unfinished Business in Bereavement Scale: Development and psychometric evaluation. Death Studies, doi:10.1080/07481187.2018.1521101.

Klingspon KL, Holland JM, Neimeyer RA and Lichtenthal WG (2015). Unfinished business in bereavement. Death Studies, 39, 387-398.

Lee SA (2020). Coronavirus Anxiety Scale: A brief mental health screener for COVID-19 related anxiety. Death Studies, doi:10.1080/07481187.2020.1748481.

Li JB, Yang A, Dou K and Cheung RYM (2020). Self-control moderates the association between perceived severity of the coronavirus disease 2019 (COVID-19) and mental health problems among the Chinese public. PsyArXiv Preprints, doi:10.31234/osf.io/2xadq.

Lundorff M, Holmgren H, Zachariae R, Farver-Vestergaard I and O'Connor M (2017). Prevalence of prolonged grief disorder in adult bereavement: A systematic review and meta-analysis. Journal of Affective Disorders, 212, 138-149.

Maercker A, Neimeyer RA and Simiola V (2016). Depression and complicated grief. In J Cook, S Gold and C Dalenberg (Eds.), APA handbook of trauma psychology. Washington, DC: American Psychological Association.

McGregor HA, Lieberman JD, Greenberg J, Solomon S, Arndt J, Simon L and Pyszczynski T (1998). Terror management and aggression: Evidence that mortality salience motivates aggression against worldview-threatening others. Journal of Personality and Social Psychology, 74, 590-605.

Menzies RE (2018). Impermanence and the human dilemma: Observations across the ages. In RE Menzies, RG Menzies and L Iverach (eds), Curing the dread of death: Theory, research and practice (pp. 3-21). QLD: Australian Academic Press.

Menzies RE and Dar-Nimrod I (2017). Death anxiety and its relationship with obsessive-compulsive disorder. Journal of Abnormal Psychology, 126, 367-377.

Menzies RE, Sharpe L and Dar-Nimrod I (2019). The relationship between death anxiety and severity of mental illnesses. British Journal of Clinical Psychology, 58, 452-467.

Mikulincer M (2018). Love, death and the quest for meaning. In RE Menzies, RG Menzies and L Iverach (Eds.), Curing the dread of death: Theory, research and practice (pp. 57-82). Australian Academic Press.

Milman E, Lee SA and Neimeyer RA (2020a). Social isolation as a means of reducing dysfunctional coronavirus anxiety and increasing psychoneuroimmunity. Brain, Behavior, and Immunity.

Milman E, Lee SA and Neimeyer RA (2020b). Social isolation and the mitigation of coronavirus anxiety: The mediating role of meaning. Death Studies, in press.

Neimeyer RA (2012). Techniques of grief therapy: Creative practices for counseling the bereaved. New York: Routledge.

Neimeyer RA (2016). Techniques of grief therapy: Assessment and intervention. New York: Routledge.

Neimeyer RA and Burke LA (2017). What makes grief complicated? Risk factors for complications in bereavement. In K Doka and A Tucci (Eds.), Living with loss: When grief is complicated. Washington, DC: Hospice Foundation of America.

Newton-John T, Chambers S, Menzies RE and Menzies RG (2020). Psychological distress and COVID-19: Estimations of threat and the relationship with death anxiety. Under Review.

Paul KI and Moser K (2006). Incongruence as an explanation for the negative mental health effects of unemployment: Meta-analytic evidence. Journal of Occupational and Organizational Psychology, 79, 595-621.

Pyszczynski T, Greenberg J and Solomon S (1999). A dual-process model of defense against conscious and unconscious death-related thoughts: An extension of terror management theory. Psychological Review, 106, 835-845.

Schimel J, Simon L, Greenberg J, Pyszczynski T, Solomon S, Waxmonsky J and Arndt J (1999). Stereotypes and terror management: Evidence that mortality salience enhances stereotypic thinking and preferences. Journal of Personality and Social Psychology, 77, 905-926. doi:10.1037/0022-3514.77.5.905.

Verdery AM and Smith-Greenway E (2020). COVID-19 and family bereavement in the United States. Applied Demography Newsletter, 32, 1-2.

World Health Organization (2019). International Classification of Disease, 11th Edition: Prolonged Grief Disorder. https:// icd.who.int/browse11/1-m/en\#/http://id.who.int/icd/entity/1183832314

World Health Organization (2020). Corona virus disease (COVID 19) Situation Report 146. https://www.who.int/docs/ default-source/coronaviruse/situation-reports/20200614-covid-19-sitrep-197.pdf?sfvrsn=5b89bdad_4

Yalom ID (2008). Staring at the sun: Overcoming the terror of death. San Francisco: Jossey-Bass.

Cite this article: Menzies RE, Neimeyer RA, Menzies RG (2020). Death Anxiety, Loss, and Grief in the Time of COVID-19. Behaviour Change 37, 111-115. https://doi.org/10.1017/bec.2020.10 